\title{
Program director and resident perspectives of a competency-based medical education anesthesia residency program in Canada: a needs assessment
}

\author{
Sylvain Boet ${ }^{1,2}$, Ashlee-Ann E. Pigford ${ }^{3}$ and Viren N. Naik ${ }^{1}$ \\ ${ }^{1}$ Department of Anesthesiology and ${ }^{2}$ Department of Innovation in Medical Education (DIME), The Ottawa Hospital \\ and University of Ottawa, and ${ }^{3}$ Department of Anesthesiology, The Ottawa Hospital Research Institute, Ottawa, \\ ON, Canada
}

Purpose: In July 2015, the University of Ottawa introduced a competency-based medical education (CBME) postgraduate program for anesthesia. Prior to program implementation, this study aimed to identify Canadian anesthesiology program directors perceptions of CBME and residents' opinion on how the program should be designed and perceived consequences of CBME.

Methods: This two-phase, qualitative study included semi-structured interviews with Canadian anesthesia program directors (Phase I) and a focus group interview with residents enrolled in the University of Ottawa time-based anesthesia program (Phase II). Both phases sought to gauge participant's perceptions of CBME. Interviews were recorded, transcribed verbatim and thematically analyzed. Results: Data was combined to protect anonymity of the six participants (three program directors and three residents). Participants spoke about the perceived advantages of CBME, the need to establish definitions, and challenges to a CBME program highlighting logistical factors, implications for trainees and the role assessment plays in CBME.

Conclusion: These findings will inform CBME implementation strategies in anesthesia programs across the country, and may assist other residency programs in the design of their programs. Furthermore, our findings may help identify potential challenges and issues that other postgraduate specialties may face as they transition to a CBME model.

Key Words: Anesthesia, Competency-based education, Medical education, Residency

\section{Introduction}

Current postgraduate medical education has been criticized for being largely unchanged from the time-based apprentice model adopted over a century ago [1]. The public is demanding more accountability from the medical profession [2] and the current model has been accused of producing physicians who are ill-equipped to deal with an increasingly complex healthcare system [3]. As a result, there is a growing global trend towards alternative models of education such as competency-based models of medical education, also called competency-based medical education (CBME) $[4,5,6,7]$. CBME programs identify the competencies that are required by an independently practicing healthcare professional and structure a training program to develop, assess, and maintain those competencies [5].

In 2011, the Future of Medical Education in Canada Postgraduate Project identified the need to shift from the
Received: December 3, 2015 • Revised: January 20, 2016 • Accepted: March 4, 2016 Corresponding Author: Sylvain Boet (http://orcid.org/0000-0002-1679-818X) Department of Anesthesiology \& Department of Innovation in Medical Education, The Ottawa Hospital, 501 Smyth Rd, Critical Care Wing 1401, Ottawa K1H 8L6, ON, Canada Tel: +1.613.737.8187 Fax: +1.613.737.8189 email: sboet@toh.on.ca
Korean J Med Educ 2016 Jun; 28(2): 157-168. http://dx.doi.org/10.3946/kjme.2016.20 eISSN: 2005-7288

(C) The Korean Society of Medical Education. All rights reserved. This is an open-access article distributed under the terms of the Creative Commons Attribution Non-Commercial License (http:// creativecommons.org/licenses/by-nc/3.0/), which permits unrestricted non-commercial use, distribution, and reproduction in any medium, provided the original work is properly cited. 
traditional apprenticeship model to CBME [8]. Pilot data from the University of Toronto Orthopedics program suggests that many residents can finish training faster than the mandatory duration of traditional training, which has the potential to optimize the costs of residency training if these findings can be scaled up across specialties and countries [9].

In July 2015 a CBME postgraduate program for anesthesia residents will be introduced at the University of Ottawa in Canada. The Royal College of Physicians and Surgeons of Canada named the new CBME programs "Competency by Design." There is, to our knowledge, currently no other postgraduate CBME program in anesthesia in Canada and only a few in the world that use the model to reduce the time required for train a specialist. Prior to program implementation, this study aimed to identify (1) Canadian anesthesiology program directors perceptions of CBME and (2) residents' opinion on how the program should be designed and perceived challenges and consequences of CBME.

\section{Subjects and methods}

\section{Ethics approval}

The Ottawa Health Science Network-Research Ethics Board (OHSN-REB \#20130282-01H) has approved the study.

\section{Study population}

All 17 directors of postgraduate anesthesia programs across Canada and current anesthesia residents $(n=50)$ from the University of Ottawa were invited to participate by email. We recruited program directors through a contact at the Association of Canadian University Departments of Anesthesia (ACUDA), who forwarded recruitment information to members and sent out repeated follow-up requests to potential participants on our behalf. Residents were recruited via email sent by the administrative staff with the university's anesthesia department. Three emails were sent and all interested participants were followed up with until they provided a response. Participants provided written consent and gave permission to have their data published.

\section{Study design}

This two-phase, qualitative interview study was conducted prior to CBME program implementation. In Phase I, all 17 Canadian anesthesia program directors were invited to participate through the ACUDA. A trained research assistant conducted semi-structured individual interviews in person or over the phone with participants. Recorded interviews were transcribed verbatim and analyzed concurrently in an iterative process using qualitative methods. Phase I data was used to develop a question guide for Phase II interviews.

Phase II was conducted after Phase I was completed. In Phase II, residents enrolled in the University of Ottawa anesthesia program were invited to participate in a focus group interview. The focus group aimed to solicit resident' opinions about CBME as a model for residency training in anesthesia and their perceived challenges and consequences of CBME. The focus group interview was transcribed verbatim.

The interviews and focus group followed the developed interview guides (Appendixes 1, 2). All transcripts (individual and focus group) were imported into NVivo 10 (QSR International, Melbourne, Australia) and thematically analyzed using the constant comparison method to synthesize data [10,11]. Employing the first three steps of the purposeful constant comparison approach [12] comparisons occurred within a single interview, between interviews within the same group and between different groups. Each interview was reviewed in its entirety and open coded to label each passage with an adequate code. 
After reviewing each interview, interviews within the same grouping (i.e., program directors) were compared and the coding strategies were combine to form an overall coding strategy. Since there was only one resident focus group, this step was not completed for this group. The combine coding strategy from the program director group was used to inform the development of the question guide for the resident focus group. After all interviews were complete and analyzed by group, interviews from the two different groups (i.e., program directors and residents) were compared to capture the overall similar and different perceptions of a CBME program.

\section{Results}

For Phase I, following the recruitment methods described in the previous section, three out of the 17 program directors were engaged. For Phase II, a question guide based on Phase I data guided one focus group interview with three current anesthesia residents (current traditional 5-year time-based program). Findings from all interviews have been combined to protect anonymity. Our goal was not to compare program directors and residents perspectives but rather to present a general overview of the perceptions and opinions of CBME prior to CBME program implementation.

The emerging themes from participants focused on the need for definitions, the advantages of CBME, and challenges (i.e., program administration, implications for trainees, and assessment) in a CBME program (Table 1).

\section{Need for a CBME vocabulary}

Before a CBME program is implemented, participants

Table 1. Sample of Program Director and Resident Perceptions to Implementing a CBME Program

\begin{tabular}{|c|c|}
\hline Theme & Quotation \\
\hline Definitions & $\begin{array}{l}\text { "I think the idea [of CBME] is to teach people in order to meet a predefined, specific standard. Whereas } \\
\text { now, the predefined, specific standard is 'can you pass the Royal College exam the first time in } 5 \text { years.'" } \\
\text { (Resident) } \\
\text { "[...] what is a specialty of anesthesia? And off-service rotations, we all feel that they add the ability } \\
\text { for us to be perioperative physicians. We're not just intra, in the Operating Room, providing a general } \\
\text { anesthetic. We are so much more than that." (Program director) }\end{array}$ \\
\hline Advantages & $\begin{array}{l}\text { "You have more direction over your own learning and your own pace." (Resident) } \\
\text { "I think a great opportunity with competency-based education is this is going to be good for the person } \\
\text { who is falling behind and identifying them earlier, giving them some things to strive for, giving them } \\
\text { some great feedback. But, what about the outstanding individuals? Is it going to allow them to move } \\
\text { quickly to proficiency." (Program director) }\end{array}$ \\
\hline $\begin{array}{l}\text { Challenges: program } \\
\text { administration }\end{array}$ & $\begin{array}{l}\text { "Nothing should stop you from saying a resident has achieved competency in a certain area, even if it's } \\
\text { before the block ends. The question is, what do we do with that week or two that is left? How can } \\
\text { we best use that?" (Program director) }\end{array}$ \\
\hline Challenges: assessment & $\begin{array}{l}\text { "It's too bad we don't get evaluated more often because I think a lot of the softer things we talk about, } \\
\text { like communicator, professional, and things like that, we recognize the staff are very poor at evaluating } \\
\text { these things. I think our patients could somehow play a role in that. I think that would take some of } \\
\text { the responsibility off the staff and you'll have people who are more appropriate to evaluate that actually } \\
\text { evaluate it." (Resident) } \\
\text { "I say, okay, this is a good one for us to do together...And they may [do] this intubation...the little nuances } \\
\text { of how to do things safely is there. And they may feel, okay, I've intubated, therefore, I'm competent. } \\
\text { Well, not really." (Program director) }\end{array}$ \\
\hline
\end{tabular}

CBME: Competency-based medical education. 
emphasized the need to form common definitions and to create a new vocabulary to guide the program. The word competency was perceived as ambiguous. Discussion of competence led to questions about incompetence or dyscompetence and how these terms are defined. Participants questioned if proficiency and competency meant the same thing; however, the majority of participants defined competency in terms of skill mastery. There were concerns about whether the definition considered overall confidence or simply the ability to perform a skill consistently. Residents spoke to the need for redefined objectives of training and standard training requirements using a competency lens and for an updated set of objectives for subspecialties.

"I think the idea [of CBME] is to teach people in order to meet a predefined, specific standard. Whereas now, the predefined, specific standard is 'can you pass the Royal College exam the first time in 5 years." (Resident)

Participants raised concerns about how to define the scope of anesthesia practice and what training is required to be an anesthesiologist. Some reconciled this professional scope based on location of practice (e.g., rural, city, teaching hospital).

“[...] what is a specialty of anesthesia? And off-service rotations, we all feel that they add the ability for us to be perioperative physicians. We're not just intra, in the Operating Room, providing a general anesthetic. We are so much more than that." (Program director)

\section{Advantages of CBME}

Participants highlighted the advantages of CBME citing: early identification of those who are advanced or require extra assistance; an accelerated program for those who excel and plan for further subspecialty training; flexibility in completing a more personalized program; regular feedback; a sense that trainees would be better prepared to take their Royal College exams; a system that could expedite the accreditation of foreign trained international medical graduates; and the benefits (financial and time) of having a more efficient training system.

"You have more direction over your own learning and your own pace." (Resident)

Echoing findings from others [6,13], participants also explained that a CBME program would facilitate feedback to the trainees and allow for setting goals and outlining strategies to address weak areas.

"I think a great opportunity with competency-based education is this is going to be good for the person who is falling behind and identifying them earlier, giving them some things to strive for, giving them some great feedback." (Program director)

\section{Challenges of CBME}

\section{1) Program administration}

Participants discussed potential administrative challenges. These concerns included administrative burden for program coordinators; issues with scheduling rotations; unpredictable changes in program size; curriculum development; the development of personalized learning programs to match different learning speeds; and available resources. There were a number of discussions about how to fill in time if someone achieves competency early in a rotation.

"Nothing should stop you from saying a resident has achieved competency in a certain area, even if it's before the block ends. The question is what do we do with that 
week or two that is left? How can we best use that?" (Program director)

Another challenge voiced was the need for administrators to ensure that those with an accelerated program were exposed to an appropriate case mix, which they perceived as required to making a competent physician.

"Now, as they become more experienced and they see more cases, do more cases, do some medicine, do some critical care, do all of this, they get better and better and better at it." (Program director)

Program directors also raised concern over the need to ensure faculty commitment, buy-in, and participation. This reflects other CBME programs that emphasize faculty engagement and support as critical elements for successful educational reform [6]. With respect to providing and supporting faculty development, there were questions raised as to how faculty will be trained to provide alternative forms of assessment.

\section{2) Implications for trainees}

Concerns were raised about the implications for trainees participating in a CBME anesthesia program, such as trainees in the existing system (time-based) may be at a disadvantage; there may be additional pressure on trainees to perform; the intensity of the CBME program is unknown; it is possible that trainees may focus on getting through the program as fast as possible and pass the assessment rather than recognizing competency on the continuum to mastery through lifelong learning; there may be stigma for those who are part of the new program; CBME program participants may be faced with additional administrative responsibilities; there may be implications for future employment with varied numbers of graduating residents each year; and it may take longer to complete the program.
"I think it's going to create a stigma. And I think, too, there is a big step up in income when you finish and you get to go out and practice. If, I tell you, you need extra time, in a way, I'm costing you money." (Program director)

While participants cautioned that there could be gaps in experience if people advanced too quickly, while others noted that the time-based system also results in missed opportunity to be exposed to rare cases.

"It's good and it's bad. I think that's the entire purpose of competency is that we will get to see all those cases ...there were some cases that I was supposed to see that I didn't see. So, I guess there is a mixed...I think time is important. There should probably be a minimum amount of time on a sub-specialty." (Resident)

Furthermore, residents emphasized the value social support provided by being part of a cohort and questioned if the trade-offs were worth it.

"It just sounds like there is more competition amongst residents. I think that is an issue that should be looked at closely because I think residents are the ones that get you through. Especially for us, it's so supportive. So, to lose that, to have some competition, and focus on time, and you don't want to finish later because then when you're applying for a job you have to say 'I was in competency and it took me 6 years because I wasn't competent." (Resident)

\section{3) Assessment/evaluation}

The implications of a CBME program on assessing competency were discussed by all participants. Questions were raised about the degree of competency required, what is an acceptable standard, minimal standard, and how to determine if someone has mastered a skill or 
achieved competency.

"I say, okay, this is a good one for us to do together... And they may [do] this intubation...the little nuances of how to do things safely is there. And they may feel, okay, I've intubated, therefore, I'm competent. Well, not really." (Program director)

Participants discussed the need for shared definitions of competency among faculty evaluating trainees. The capacity for faculty to provide rigorous and frequent assessment to ensure that trainees achieve competence before progressing to further stages of training was brought into question. There were concerns expressed about subjectivity and validity of assessment, as well as the relevance of existing tools and checklists. Overall, participants were unclear about the exact delivery and structure of assessment in a CBME context. A large component of the interviews highlighted the grey areas of assessment and participants raised questions about how existing frameworks and tools (i.e., Canadian Medical Education Directions for Specialists [CanMEDS], objective structured clinical examination [OSCE]) will be integrated into this form of curricula and how technical and non-technical skills will be assessed. Furthermore, some participants questioned if the faculty have reached the standard setting for competence they will be assessing.

Frequency of observation, assessment and feedback were discussed. Both program directors and residents noted that the processes for identifying and assisting struggling residents in a CBME program are unclear. One important area of assessment where ambiguity was highlighted was communication skills. In the current model, program directors reported that it was challenging to assess the acquisition and evaluation of communication skills. Residents suggested that more frequent, consistent, personalized feedback from the same staff could improve assessment of trainees. This is supported by the literature, which emphasizes the value of direct observation and workplace based assessment to provide meaningful formative feedback and opportunities for growth [14]. One suggestion to improve feedback was to involve assessment from team members (e.g., nurses and nurse educators) as well as patients.

"It's too bad we don't get evaluated more often because I think a lot of the softer things we talk about, like communicator, professional, and things like that, we recognize the staff are very poor at evaluating these things. I think our patients could somehow play a role in that. I think that would take some of the responsibility off the staff and you'll have people who are more appropriate to evaluate that actually evaluate it." (Resident)

\section{Discussion}

Stakeholder perspectives have revealed potential unintended consequences and concerns relating to the implementation of a CBME program. Echoing the literature, one of the greatest concerns raised by participants was the need for shared definitions of competency and related terms when designing a CBME curriculum [15]. Even though participants highlighted potential challenges for program administration and trainees as well as logistical issues with providing assessment, they also spoke to the merits of a CBME program (i.e., a personalized program to match trainee skill; regular feedback; improved preparation for exams; and a more efficient training system). Thus, based on our data, we hypothesize that many stakeholders (program directors and residents) will recognize the value of a CBME 
program and support the implementation of CBME for anesthesia residency, but consider CBME to be a nuanced topic with many perceived advantages and challenges. If we extrapolate further form our data, we may hypothesize that by addressing the perceived barriers and reinforcing the perceived strengths identified by stakeholders, program administrators and policy makers will facilitate the successful implementation of a CBME curriculum for anesthesia residency.

For a program to be successful, it is imperative that all parties involved work within a common framework that has shared definitions based on up-to-date evidence. Although our findings reinforce existing knowledge about the perceived advantages and challenges of CBME, these findings suggest that new developments in CBME are not being effectively transmitted to stakeholders. For example, participants and previous research identified institutional difficulties in organization and evaluation of CBME, as well as the challenges with breaking the complex construct of the competent practitioner into distinct competencies [15]; however, there have been a number of advances in these areas $[16,17,18]$. In particular, it should be noted that concerns about assessment and the best way to approach competency have been largely improved by the development of frameworks such as CanMEDs [7], and by breaking competencies down into entrustable professional activities (EPAs) $[4,17,18]$. EPAs are essentially "units of competencies in context." As trainees progress throughout their careers, they have to demonstrate competency in all EPAs via completion of a series of modules with several milestones in each of them [19]. The use of EPAs and milestones has been proposed as the way forward to help address issues with assessment and curricula development in CBME programming [16]. The anesthesia program directors and residents included in this study did not systematically convey these concepts suggesting that it may be necessary to implement additional strategies to translate updated information about CBME programming to help curb concern among stakeholders.

Several hypotheses may explain why study participants may be unaware of the developments in CBME. It is possible that there the literature on the advanced stages of planning and implementing CBME programs still needs more development or that literature alone may not be the best approach to disseminate evidence to stakeholders. Alternative dissemination strategies such as workshops, rounds, and podcasting may contribute to fill the gap. Therefore, we suggest that it is imperative that programs engaging in $\mathrm{CBME}$ share their experiencesboth positive and negative-using multiple formats of dissemination, so that the entire community can learn from it. This study partially contributes to addressing this gap. These findings will inform CBME implementation strategies in anesthesia programs across the country, and may assist other residency programs in the design of their programs. Furthermore, our findings may help identify potential challenges and issues that other postgraduate specialties may face as they transition to a CBME model.

The opinion of program directors nationally is key to the acceptance and generalized of the anesthesia CBME program at the national level. Unfortunately, we had a low response rate with $18 \%$ of program directors and $6 \%$ of residents participating. Our limited success in recruiting program directors may suggest a lack of interest in implementing the new CBME program. If true, there could be a number of challenges in the implementation of the new Royal College CBME curricula. Although low recruitment prevented data saturation, qualitative research is generally viewed as hypothesis-generating research (as opposed to hypothesis-driven), and results are not expected to be generalizable. Our findings provide a contextualized understanding of stakeholder 
experience.

In conclusion, as more postgraduate specialties programs switch to a CBME model across Canada and internationally [20], our findings may help guide them on the potential challenges and issues that they may face.

ORCID: Sylvain Boet: http://orcid.org/0000-0002-1679-818X; Ashlee-Ann E. Pigford: http://orcid.org/0000-0001-5028-8792; Viren N. Naik: http://orcid.org/0000-0002-2387-7329

Acknowledgements: The authors thank the program directors and residents who agreed to participate in this study. The authors also thank Dr. Dylan Bould for his contribution to this study and Francine Hart for her technical assistance.

Funding: This study was supported by an Educational Initiatives in Residency Education (EIRE) Grant from the University of Ottawa, Ottawa, ON, Canada.

Conflicts of interest: None.

\section{References}

1. Cooke M, Irby DM, Sullivan W, Ludmerer KM. American medical education 100 years after the Flexner report. N Engl J Med 2006; 355: 1339-1344.

2. Boelen C, Woollard B. Social accountability and accreditation: a new frontier for educational institutions. Med Educ 2009; 43: 887-894.

3. Fraser SW, Greenhalgh T. Coping with complexity: educating for capability. BMJ 2001; 323: 799-803.

4. Iobst WF, Sherbino J, Cate OT, Richardson DL, Dath D, Swing SR, Harris P, Mungroo R, Holmboe ES, Frank JR. Competency-based medical education in postgraduate medical education. Med Teach 2010; 32: 651-656.

5. Frank JR, Snell LS, Cate OT, Holmboe ES, Carraccio C, Swing SR, Harris P, Glasgow NJ, Campbell C, Dath D,
Harden RM, Iobst W, Long DM, Mungroo R, Richardson DL, Sherbino J, Silver I, Taber S, Talbot M, Harris KA. Competency-based medical education: theory to practice. Med Teach 2010; 32: 638-645.

6. Ibrahim $\mathrm{H}$, Al Tatari $\mathrm{H}$, Holmboe ES. The transition to competency-based pediatric training in the United Arab Emirates. BMC Med Educ 2015; 15: 65.

7. Frank JR, Danoff D. The CanMEDS initiative: implementing an outcomes-based framework of physician competencies. Med Teach 2007; 29: 642-647.

8. A collective vision for postgraduate medical education: the future of medical education in Canada postgraduate project [Internet]. The Association of Faculties of Medicine of Canada; 2012 [cited 2015 June 24]. Available from: https://www.afmc.ca/future-of-medicaleducation-in-canada/postgraduate-project/pdf/FMEC_PG _Final-Report_EN.pdf.

9. Alman BA, Ferguson P, Kraemer W, Nousiainen MT, Reznick RK. Competency-based education: a new model for teaching orthopaedics. Instr Course Lect 2013; 62: 565-569.

10. Pope C, Ziebland S, Mays N. Qualitative research in health care: analysing qualitative data. BMJ 2000; 320: 114-116.

11. Glaser BG. The constant comparative method of qualitative analysis. Soc Probl 1965; 12: 436-445.

12. Boeije H. A purposeful approach to the constant comparative method in the analysis of qualitative interviews. Qual Quant 2002; 36: 391-409.

13. Takahashi SG, Waddell A, Kennedy M, Hodges B. Innovations, integration and implementation issues in competency-based education in postgraduate medical education [Internet]. The Association of Faculties of Medicine of Canada; 2011 [cited 2015 June 24]. Available from: https://www.afmc.ca/pdf/fmec/19_Glover \%20Takahashi_Competency-based\%20Education.pdf.

14. Miller A, Archer J. Impact of workplace based assessment 
on doctors' education and performance: a systematic review. BMJ 2010; 341: c5064.

15. Brooks MA. Medical education and the tyranny of competency. Perspect Biol Med 2009; 52: 90-102.

16. Touchie C, Ten Cate O. The promise, perils, problems and progress of competency-based medical education. Med Educ 2016; 50: 93-100.

17. Ten Cate O. Nuts and bolts of entrustable professional activities. J Grad Med Educ 2013; 5: 157-158.

18. ten Cate O, Scheele F. Competency-based postgraduate training: can we bridge the gap between theory and clinical practice? Acad Med 2007; 82: 542-547.

19. Carraccio C, Iobst WF, Philibert I. Milestones: not millstones but stepping stones. J Grad Med Educ 2014; 6: 589-590.

20. Competence by design: reshaping Canadian medical education [Internet]. Royal College of Physicians and Surgeons of Canada; 2014 [cited 2015 June 24]. Available from: http://www.royalcollege.ca/common/documents/ educational_initiatives/rc_competency-by-design_ebook_e. pdf. 


\section{Appendix 1. Question Guide: Protocol for Semi-Structured Interviews with Anesthesia Program Directors}

The purpose of this interview is to identify (1) if there is a perceived need for "competency by design", i.e., competency-based medical education (CBME) in Canadian anaesthesiology programs, (2) to solicit national opinion on how such a program should be designed and in particular which modules should be mandatory, and $(3)$ to assess potential challenges and unintended consequences of CBME.

It is recognized in the literature that competency-based programs are a definite new direction in medical education. However, there are some ambiguities as to what this means in theory, and some doubts about what this will mean in practice.

1. In theory, some controversy exists in the literature regarding the meaning of the word "competency."

1) In general terms, how would you define "competency," in terms of anesthesia residency?

2) How does a resident acquire "competence?"

3) How do you know when a resident is competent or not to begin practice?

2. CBME breaks down the knowledge, skills and attributes required to practise anaesthesia into component competencies, which the resident acquires at their own pace and with some measure of programming discretion.

1) How does the new model — acquisition of a set of competencies as a basis for assessment — compare with the more traditional time-based model of training?

2) What preparatory work or restructuring would be necessary before a given school could adopt a CBME format?

3. In practice, CBME would allow students to progress at their own rate of learning and skill acquisition. This may well create the situation wherein every student could be at a different, individualized stage of progress.

1) How would something like this be administrated?

2) Where do you think real problems may lie? Unintended consequences?

3) What about the stigma of being a 6-year graduate as opposed to say a 4-year graduate, in terms of professional stature?

4. Current programs in anaesthesia utilize off-service rotations to prepare residents for general exams, and to round out their experience; in cardiology, respirology, nephrology, ICU, etc. These are time-consuming and may not directly relate to competence in anaesthesiology. 1) In terms of program design, what could be done to, first, ensure competence in anaesthesiology, and second, to allow for exposure to these other specialities?

2) If it were strained down to its essence, what is the core of anaesthesia competence? What - if any — parts of current programming could be modified, replaced, shifted to self-directed learning, or maybe reserved to fellowships?

5. One parting shot: CBME, the next best thing, or a big mistake? What do you think? 


\section{Appendix 2. Question Guide: Protocol for Focus Resident Focus Groups}

Preamble: The purpose of this focus group is to discuss the findings of Phase I of our study, and to solicit your feelings and opinions about "competency by design," i.e., competency-based medical education (CBME) as a model for your residency training in anesthesia.

Please feel free to share whatever is on your mind in this regard. All comments are open to discussion as well. Please respect all members of the group, and their opinions. Everyone will be afforded ample time to speak.

1. To begin, I would like to hear some general comments from around the table:

1) What do you know about competency-based education?

a. Prompt: How do you define it?

b. Prompt: Do you think there is a difference between being competent vs. being proficient?

2) What have you heard about CBME in anesthesia?

3) Who is discussing it? In what context?

2. We have a few questions regarding CBME and its implementation.

1) What do you see as a competent anaesthesiologist?

2) How do you think competency should be assessed?

a. Prompt: What do you think is the best way to assess students in a CBME program?

b. Prompt: Continuing assessment vs. exam?

c. Prompt: Who is best situated to evaluate residents in a CBME program?

3) What do you think the role of Canadian Medical Education Directions for Specialists is in a CBME program?

3. We are curious about your thoughts on how the program will change resident's experiences.

1) In what ways do you think the implementation of a CBME curricula will change the focus of anesthesia residency?

2) CBME results in a flexible time scale for the completion of residency. Do you think this will impact residents'...

- Clinical exposure?

a. Prompt: Will this impact the type of cases residents are exposed to?

- Acquisition of nontechnical skills?

b. Prompt: Teamwork, communication etc...

- Time spent learning from a master?

- Ability to conduct their research projects?

4. Next, we would like you to speak to your perspective on the implementation of the program.

1) What do you think needs to be changed in the existing program structure to facilitate CBME?

a. Prompt: With respect to curriculum?

b. Prompt: With respect to program administration, logistics and planning?

5. CBME is coming to Ottawa in 2015. It will not affect any of you, nor require any changes to your current program structure. However, some future grads could begin practice a lot quicker than any of you will. And by the same token, some may take a lot longer.

1) How do you feel about this?

2) How do you imagine you'll feel toward future colleagues at either end of this spectrum?

a. Prompt: Do you think it will create competition between CBME vs. traditional streams?

In what ways?

3) Can you list some of the advantages you foresee for residents in a CBME program?

4) Can you list some of the disadvantages foresee for residents in a CBME program?

5) Who do you think might be interested in this type of program (type of residents)? 
Sylvain Boet, et al: CBME in anesthesia residency

a. Prompt: How do you think it will impact IMG's (international medical graduates)?

(Residents may speak about those looking for a shorter program; those who have jobs lined up; those looking for a longer program

- facilitated family/parental leave)

6. Consider this your opportunity to inject something directly into the decision-making process.

1) What would you say to the directors who are implementing these programs?

2) What do university departments need to hear from the resident perspective? 